\title{
Digital Transformation Initiative in a Public Sector Organization: Stakeholder Viewpoints and Responses in Ghana
}

\author{
Michael Nartey Agbeko \\ University of Ghana \\ mnagbeko@st.ug.edu.gh
}

\author{
John Effah \\ University of Ghana \\ jeffah@ug.edu.gh
}

\author{
Richard Boateng \\ University of Ghana \\ richboateng@ug.edu.gh
}

\begin{abstract}
The importance of digital transformation initiatives for contemporary organizations has been demonstrated in research and practice. However, stakeholder viewpoints and responses to such initiatives in the public sector are less understood. We draw on the stakeholder theory to empirically examine how a public sector transformation initiative is shaped by various stakeholders' viewpoints and responses. This initiative involves an e-procurement platform implementation to transform procurement processes and activities in the developing country context of Ghana. We find that responses from the stakeholder groups influence which viewpoints are realized or not and what factors shape the realizations. The analysis demonstrates that: (1) Failure to realize stakeholder viewpoints is likely to affect benefits derived from public sector digital transformation initiatives; (2) Success of digital transformation initiative pivots around analysis of stakeholders' responses to the outcomes of such projects; (3) Lack of appropriate technological infrastructure constrains digital transformation initiatives in the public sector.
\end{abstract}

\section{Introduction}

Digitalization is the complex sociotechnical phenomena and procedures of adopting and utilizing digital innovations by individuals, organizations, and the broader society [25]. Digitalization has enabled the creation of turbulent and competitive environments through rapid headways in computerized innovation [25, 22]. Through digitalization, digital business models are more favored and traditional value propositions are revised, creating low entry barriers [16]. Digitalization is making traditional organizations struggle thus engaging in the process of digital transformation [34, 43]. Digital transformation is propelled by the collective influence of several digital innovations [46]. As a process of organizational change, digital transformation is exhibited in new operational procedures, value propositions, and business models [59]. Such changes lead to the espousal of new work systems [7] which also leads to redesign of current structures [49].

Digital transformation initiatives in the public sector involve the participation of different stakeholders with diverse viewpoints and responses during implementation [41, 47]. Stakeholder viewpoints are defined as the set of system services required by stakeholders to do their duties [33]. Stakeholder responses, however, are referred to as the set of reactions manifested by stakeholders as IT is introduced into their work environments [9]. Different stakeholders even within the same stakeholder group may have different viewpoints and responses which may be supportive or conflictive [19]. This makes the implementation of such initiatives difficult because of the subjective contributions from the stakeholders [10, 21]. ICT setup that propels digital transformation is diverse and spans across ever increasing user base with different viewpoints and resources [17]. As a result, problems associated with implementing digital transformation initiatives are more pronounced [40]. One aspect of implementation is to appraise how well a digital transformation initiative achieves its objectives [38]. In appraising digital transformation initiatives, the interests of relevant stakeholders are determined and synthesized to establish common judgment [8].

IS research focusing on strategy, design and development of digital transformation are quite substantial [30, 41]; however, studies aiming at implementation are less. Accordingly, we employ the stakeholder theory [36] as analytical lens and qualitative interpretive case study [51] to gain rich insight into the implementation of an eprocurement system, a digital transformation initiative in the public sector with the aim of converting manual procurement processes and activities into digital forms in Ghana. This study extends the IS literature on implementation to the context of public sector digital transformation. Studies on public sector digital transformation initiatives are important because they can help researchers and practitioners develop more understanding of the barriers and enablers of government digitalization. Thus, the research question we address is 
how do stakeholders' viewpoints and responses shape the transformation of manual procurement processes and activities to digital formats in the public sector? Answering the question, we studied a government initiative that was intended to transform manual procurement processes into digital formats to understand how stakeholders' viewpoints and responses shape such transformation projects in the public sector.

The paper is structured in this way. In section 2 , we review the current literature on digital transformation initiatives in the public sector by looking at the implementation and maintenance of governmental services from traditional processes to digital platforms, pointing out that stakeholders' perspective on digital transformation initiatives in the public sector are under researched. Thus, we reflect on the concepts of the stakeholder theory as theoretical lens to investigate the influences of interested parties in public sector digital transformation initiatives to enhance the current understanding of the underpinnings of digital innovation induced change. In section 3, we describe and justify interpretive qualitative empirical research approach as the study's methodology and present the case description and analysis of a public sector digital transformation initiative involving the implementation of an e-procurement platform to discover the influences of interested parties in section 4 and 5 , respectively. We discuss the analysis in section 6 and conclude the paper in section 7 .

\section{Theoretical Background}

\subsection{Public Sector Digital Transformation}

Digital Transformation has been used interchangeably with IT-enabled organizational transformation [7]. However, IS scholars interpret digital transformation as accumulative changes, at different levels of the organization, caused by implementations of digital solutions [17]. Public sector digital transformation involves the process of developing, implementing and maintaining governmental services from traditional processes onto electronic platforms [41]. Digital transformation infrastructure produced to handle government services are mostly in the form of web-based applications [30]. Digital transformation infrastructure gives stakeholders advantages such as personalization, single-sign-on to all applications, and improved content management ability from different sources [26]. Such infrastructure provides the benefits of improved government services and equity in information dissemination as well as cost reduction [27].

Public sector digital transformation goes beyond innovation [18] into proper data management and making business process modifications [15]. It changes the mindset of users on the functionalities of digital systems [11].
Though public sector digital transformation is viewed as a means of improving democracy, its implementations are saddled with sociotechnical challenges that go beyond just the introduction of technology [13]. Some of the challenges are identifying, knowing, and understanding user needs and expectations [17]; limited network infrastructure [28]; and finding approaches to deal with the complexities as well as contradictions in large public sector institutions taking into account the economic values and democratic benefits of the context [7], and extensive stakeholder engagement throughout digitalization [28].

Tried as most researchers and practitioners have, the challenge of frequent failures of digital transformation attempts in the public sector continues to persist [1]. This is because public sector services and stakeholders are highly heterogeneous and scattered over large geographical areas [28]. These services are ordinarily provided through complex collaborations and correspondence framework among various government divisions [46]. The complexities are as a result of organizational factors such as size, procedure for change and the resistance by stakeholders, novelty, the impact on end users as well as the politics involved [6]. Therefore, such public sector digital transformation requires developers and implementers to seek the efforts of influential stakeholders conveyed over the social system, who regularly communicate with each other [46]. In general, studies [3, 5] on public sector digital transformation suggest that no one category of activities influences the outcomes of such initiatives. That is to say, there ought to be equivalent regard for the social and also the technical needs. The reason being that such digital transformation includes associations between extensive partners inside a sociotechnical framework, which considers technical, organizational and personal needs; hence, there is a demand for a comprehensive view of interactions [4].

Despite the existence of these studies, they fail to unearth knowledge on how stakeholders' viewpoints and responses shape digital transformation initiative processes and activities in the public sector. Thus, it is important to understand how public sector digital transformation initiatives are influenced by participants' perspectives.

\subsection{Stakeholder Theory}

The stakeholder theory serves as the guiding lens for this study. Advanced from the business management discipline, this theory advocates addressing the concerns of individuals, organizations and communities who may influence or may be influenced by the decisions an organization makes [35, 51]. A stakeholder refers to any group, individual or organization that has practical concerns for the effective application of an IS and can be impacted or impact how the system is used and why [12]. The 
stakeholder theory is composed of three interrelated and mutually supportive elements: normative, descriptive, and instrumental [24]. The normative element of the theory assumes the existence of diverse stakeholder groups and their interests in the design and implementation of every information system [39]. The descriptive element involves defining and identifying stakeholders and demonstrating their importance towards the performance and evaluation of digital infrastructure [36]. According to Donaldson and Preston [20], the instrumental aspect of the theory primarily refers to efforts in investigating the effectiveness of a stakeholder.

The fundamental principle of the theory is salience. Salience answers the question why some stakeholder claims are attended to while others are not. According to Mitchell, Agle, and Wood [36], salience is composed of the attributes of power, legitimacy, and urgency. Stakeholders possessing all three attributes are more salient towards managers than stakeholders who only possess one or two of the attributes and are thus termed definitive stakeholders [23] in the typology. Both stakeholders and salience represent dynamic phenomena, which should be analyzed regularly. Stakeholder theory has been employed severally in the IS literature and such literature focus on design, development, implementation, and adoption of IS [14, 23, 29].

This study maintains a practical focus on public sector digital transformation initiative involving the interests of heterogeneous stakeholder groups. Since the descriptive and normative elements of the stakeholder theory acknowledges the existence of multiple stakeholder groups and their diverse and legitimate interests in procedural and/or substantive aspects of corporate activities [23, 39], they are applied in this study to understand the effects of different stakeholder groups interests on a public sector digital transformation initiative. Furthermore, this study applies the salience principle [35] and the normative element [19] of the theory to present stakeholder group interests as viewpoints and responses. Here, viewpoints refer to the required procurement processes and activities by stakeholder groups before the transformation initiative and responses are the reactions of stakeholder groups to the required procurement processes and activities after the transformation initiative. The transformation initiative is the implementation of an e-procurement platform to transform public sector procurement processes and activities in Ghana from manual to digital formats. In IS studies, stakeholders have been identified based on a particular research purpose. For example, while Singletary et al. [44] identify stakeholders as managers, IT professionals, and end-users, Sedera et al. [43] recognize stakeholders as "Process owners", "Strategic owners", and "Operational users", among others.

In this study, we identify relevant stakeholder groups who played major roles in the government initiative to transform manual procurement processes and activities into digital formats to include officials from the central government, procurement entities (PEs), the regulator, and supplier organizations (SO). These are also the main stakeholders that are influenced by the e-procurement platform after the implementation. This is because while the central government is the initiator and the one who paid for the e-procurement platform and its implementation, procurement entities are public sector agencies who procure goods and services in their line of duty using the eprocurement platform. Also, the regulator is the governmental agency that regulates public procurement activities in the country and manages the e-procurement platform, and the supplier organizations provide goods and services to public sector agencies through the biding of contracts on the e-procurement platform.

\section{Research Setting and Methodology}

As part of a larger research project, this study has been conducted as an interpretive qualitative single case study [50] in a public sector agency in Ghana. Ghana is an emerging economy in West Africa with a population of about 30 million as of 2019. Being a democratic country with numerous political parties, elections are held every four years. The country for a long time lacked a good electronic procurement system. This posed several challenges such as corruption and procurement malpractices to the socio-economic development of the country. To address these challenges, the government launched an e-procurement platform for the public sector. This current study presents an assessment of this initiative from the perspective of stakeholder groups. The case organization for the study is the Public Procurement Authority (PPA), a government agency in charge of regulating public procurement in the country. PPA was selected because it is responsible for the implementation of the Ghana Electronic Procurement System (GHANEPS), a digital platform that is supposed to transform manual procurement processes and activities into digital formats in the public sector.

Given the purpose of the study, interpretive single case study [37] was employed to understand how the viewpoints and responses of the different stakeholder groups in the procurement ecosystem shaped the e-procurement platform implementation. Interpretive case study was used primarily because it falls in line with the view that what is seen as reality and the knowledge thereof are constructed socially between the researcher and the respondents, particularly when the researcher wants to explore a reality within a complex real-world context [37]. Consequently, we collected data from multiple sources including interviews, observations, document, and media news perusal. This is in conformity with interpretive research where many data sources can be used by a researcher to gather data [56]. 
Interviews were conducted between 1st October 2019 and 30th January 2020. We used purposive sampling as well a sword-of-mouth i.e. snowballing to identify the various stakeholder groups and interviewees. The identified interviewees represented the various stakeholder groups because they played major roles in the implementation of GHANEPS. The interviewees included officials from stakeholder groups such as the central government, the regulator, procurement entities, and supplier organizations. In all, 13 respondents were interviewed at their own convenience with sessions recorded upon gaining consent. Interviews were semi-structured [37] and lasted between 30 and 45 minutes. Table 1 shows the stakeholder groups, interviewees and number of interviews carried out.

Table 1: Interviews

\begin{tabular}{llc}
\hline Stakeholder Groups & Interviewees & $\begin{array}{l}\text { No. Of } \\
\text { Interviews }\end{array}$ \\
\hline Central Government & Senior Official & 1 \\
Regulator & Deputy CEO & 1 \\
& Head of MIS & 2 \\
Public Procurement & IT Officer & 1 \\
Entities & Head of Entity & 2 \\
Supplier Organizations & Staff of Entity & 2 \\
& Head of Organization & 2 \\
\hline Total & Staff of Organization & 2 \\
\hline
\end{tabular}

Interviews were transcribed and notes were arranged to make logical meanings. We read the transcribed data several times to gain broad understanding of responses and how they contribute to the research purpose. We conducted data analysis iteratively between interview data, data from the other sources, and relevant literature findings in order to seek data confirmation and validation. Where necessary, interviewees were followed up to verify emerging findings according to the principle of hermeneutics [31]. Following hermeneutics cycles [31] for reliability and validity, we concluded analysis of research finding when no new and relevant insights were further found.

We applied inductive coding techniques to analyze the acquired data i.e. transcribed interview as well as data from our observations, document, and media news. We first carried out data reduction by synthesizing the transcribed and secondary data into a starting point document covering the implementation of GHANEPS. Here, we arranged the implementation process in a chronological order with the aim of facilitating the understanding of the causal link between critical events. Following data reduction, we coded the transcribed data using open thematic content analysis. As a first step, we traced the various phases in GHANEPS implementation taking notices of themes such as expectations and reactions of stakeholders. We next organized the expectation and reactions into viewpoints and responses respectively, and mapped them with their corresponding stakeholders. Subsequently, we analyzed the outcomes of the implementation based on the established stakeholder viewpoints and responses to determine their effects on the implementation process.

\section{Case Description}

\subsection{Background}

Accessing most public services in an emerging economy such as Ghana can be very challenging. This may lead to various degrees of frustrations. Various governments over the years have tried to reduce these frustrations through the enactment of laws and policies but have been largely unsuccessful. The reasons for the unsuccessful alleviation of the frustrations in the public sector are bureaucracy among government workers, lack of systems to easily identify citizens, delays in document processing due to lack of resources, and unprofessional attitude of most public servants. This has resulted in the lack of trust by most citizens in Ghana to accessing governmental services. To address this, the government decided to carry out a number of e-government initiatives known as e-transform projects. The e-transform projects, of which the Ghana Electronic Procurement Platform (GHANEPS) is part, is a set of e-government projects intended to be used by government to transform the provision of goods and services in the public sector. In order to address the challenges that plaque public procurement in the country, government in 2008 decided to roll out the electronic procurement platform.

\subsection{The Implementation of GHANEPS}

GHANEPS is a web-based, collaborative system, developed in accordance with the requirement of the public procurement law (Act 663), to facilitate public procurement processes and activities in Ghana. It offers a secure, interactive, dynamic environment for carrying out procurement of all categories and complexity or value. GHANEPS supports processes of procuring goods, works, consultancy, non-consultancy and disposal of assets. The system supports various public procurement procedures, including user registration, tender notification, tender preparation and submission, online tender evaluation, contract awarding, creation and management of catalogue, creation and management of framework agreements, and auctions and payments.

The implementation of GHANEPS has evolved since 2012. In 2012, the central government engaged a consultant (Pricewaterhouse Coopers) to study the feasibility of developing and implementing an e-procurement platform 
for the country. Stakeholder discussions took place and the vision, mission, objectives, and communication strategy for the platform established. The year 2012 also saw the assessment of the country's technological infrastructure capacity and internet connectivity with a comprehensive report presented to the central government. The year 2013 saw the development of a strategy and an action plan for the building and implementation of the e-procurement platform, the design of an electronic Ghana Procurement (EGP) system and standard tender document prepared for selection of application service provider (ASP). There was a break in the implementation of the procurement system in 2014 and 2015 due to the unwillingness of the central government to continue with the implementation of the platform.

In 2016, the central government rekindled her interest in the development and implementation of the e-procurement platform. The following activities were thus carried out in that year: launch of tender for the selection of ASP, evaluation of tenders, and the selection of the ASP. Then in 2017 there were negotiation and award of contract to the ASP, inception meetings held with stakeholders by the ASP, functional requirement specifications (FRS) and system requirement specifications (SRS) developed by the ASP with the other stakeholders. The year 2018 then saw the following taking place: Acceptance of FRS and SRS by the stakeholders, testing for integration partners and complete system configuration, final stakeholders meeting, conduct of user acceptance test (UAT), and piloting of the e-procurement platform. In 2019, some practice sessions were held for selected procurement entities and supplier organizations. The platform was officially launched in April, the system went live in May and phase two of the project was launched in October 2019. "This eprocurement platform is expected to enhance transparency in public procurement processes and activities, provide a common platform for use by public institutions for procurements and public financial management, as well as enhance competition by facilitating increased participation of service providers for government contracts" [A senior official of the central government].

The Public Procurement Authority (PPA) is the regulatory body established in 2003 by law (Act 663) to be responsible for the effective management of procurement activities in Ghana. The regulator through GHANEPS seeks to ensure fairness, transparency, and non-discrimination in public procurement in order to promote a competitive local industry and increase the confidence of varied stakeholders in public procurement processes in the country and beyond. "Because of the envisaged benefits of the e-procurement platform, we anticipate that our work as the regulator will be less tedious. The platform will enable us to easily manage the activities of procurement entities and coordinate their work with supplier organizations" [A deputy chief executive officer of the regulator].

Though the regulator envisaged benefits, there were challenges with the implementation. One major challenge was the unwillingness of some of the procurement entities to cooperate with the regulator because they fear that the eprocurement platform will reduce the money they make during tendering. Another challenge was the fear that the ASP, a foreign company, was hosting the e-procurement platform. The reason for this is explained as "We are supposed to host the e-procurement platform here in Ghana. However, the public agency responsible for hosting the platform lacks the necessary infrastructure. Therefore, the central government asked the application service provider to host the platform in a foreign land for a while, as the needed infrastructure is put in place" [Head of MIS of the regulator].

Procurement entities or public sector agencies are governmental institutions that purchase goods and services as they perform their daily activities. Though public sector agencies are supposed to be the main users of the platform, they did not show much enthusiasm in support of the implementation of the system. "While the development and implementation of the e-procurement platform is good, the government has not taken into consideration ICT deficiencies of the public sector. We lack the necessary ICT tools to effectively use the platform. For example, as a public entity, we need internet data to connect to the platform and use it, but data is expensive and occupies a considerable portion of our budget" [Head of a procurement entity].

Another head of a procurement entity observed that "Since the e-procurement platform is a new system that the government is championing, we need to train our staff responsible for procurement. However, some of them have to travel even from the other regions to Accra for the training and this is costing us manpower hours and money".

Supplier organizations are individuals and private organizations that provide goods and services to public sector institutions. A supplier of public goods or services must first register with the regulator in order to bid for a tender. The regulator approves the company's registration and basic company information is exported to the eprocurement platform. The supplier company receives an email with a transaction number and first login details. Using URL received in the email, the supplier logs in into the platform, enter the transaction number received in the email for first user login and register as supplier administrator. The supplier administrator can then create login accounts for other users, reset passwords, view and edit other user accounts, and edit the organizational details and the UNSPSC code on the platform. "Though the $e$ procurement platform makes the tendering process quite easy and limits physical contact with procurement officers 
of public sector agencies, we need to buy internet data for tender bidding which is expensive and sometimes internet connectivity becomes very slow and unstable, which makes it difficult to bid for tender online" [A procurement officer at one of the supplier organization].

\section{Analysis of Findings}

The research question that motivated this study concerns how stakeholder groups' viewpoints and responses shape the transformation of manual procurement processes and activities to digital formats in the public sector. The case study findings raise a number of interesting issues for analysis and discussions. However, in line with the research question and the stakeholder theory analytical lens, this section focuses on the initial viewpoints or expectations of stakeholder groups, outcomes of viewpoints, key issues raised as responses to the outcomes and their effects on the e-procurement platform implementation as in table 2 .

The findings reveal that while some initial viewpoints of the stakeholder groups were achieved during the implementation of the e-procurement platform, others were not. Furthermore, there were a number of factors that influenced the viewpoints that were implemented and those that were not implemented.

Table 2: Stakeholder viewpoints, outcomes, responses and effects

\begin{tabular}{|c|c|c|c|c|}
\hline $\begin{array}{c}\text { Stakeholder } \\
\text { Group }\end{array}$ & Viewpoints & $\begin{array}{c}\text { Outcome } \\
\text { (Implemented) }\end{array}$ & Responses & Effects \\
\hline $\begin{array}{l}\text { Central } \\
\text { Government }\end{array}$ & $\begin{array}{l}\text { Transform provision of goods and services } \\
\text { Enhance procurement sanity } \\
\text { Improve financial management practices } \\
\text { Adhere to international best practices }\end{array}$ & $\begin{array}{l}\mathrm{N} \\
\mathrm{N} \\
\mathrm{N} \\
\mathrm{Y}\end{array}$ & $\begin{array}{l}\text { Central government lack of interest } \\
\text { Lack of infrastructure to host the e- } \\
\text { procurement platform } \\
\text { Joining of international procurement } \\
\text { bodies } \\
\text { Promulgation of relevant procurement } \\
\text { laws }\end{array}$ & $\begin{array}{l}\text { Break in project } \\
\text { implementation } \\
\text { E-Procurement } \\
\text { platform hosted in } \\
\text { another country }\end{array}$ \\
\hline Regulator & $\begin{array}{l}\text { Provide a platform for procurement activities } \\
\text { Enhance competition among supplier } \\
\text { organizations } \\
\text { Shorten procurement processes and cycles } \\
\text { Reduce corruption and procurement mal- } \\
\text { practices } \\
\text { Promote environmental sustainable } \\
\text { development }\end{array}$ & $\begin{array}{l}\mathrm{Y} \\
\mathrm{Y} \\
\mathrm{Y} \\
\mathrm{N} \\
\mathrm{N}\end{array}$ & $\begin{array}{l}\text { Fear of losing financial rewards from } \\
\text { contractors } \\
\text { Lack of needed infrastructure to } \\
\text { successfully host e-procurement } \\
\text { platform. }\end{array}$ & $\begin{array}{l}\text { Unwillingness of } \\
\text { public sector agencies } \\
\text { to support e- } \\
\text { procurement platform } \\
\text { implementation } \\
\text { Fuelling of Corruption } \\
\text { Periodic unavailability } \\
\text { of e-procurement } \\
\text { platform } \\
\text { Unabated use of paper }\end{array}$ \\
\hline $\begin{array}{l}\text { Procurement } \\
\text { Entities }\end{array}$ & $\begin{array}{l}\text { Public agency and user registration } \\
\text { Annual procurement plan preparation } \\
\text { Creation of procurement competition } \\
\text { Submission of tender documents } \\
\text { Advertisement of tenders } \\
\text { Tender evaluation, contract award and } \\
\text { acceptance }\end{array}$ & $\begin{array}{l}\mathrm{Y} \\
\mathrm{Y} \\
\mathrm{Y} \\
\mathrm{Y} \\
\mathrm{Y} \\
\mathrm{Y}\end{array}$ & $\begin{array}{l}\text { Lack of necessary ICT gadgets to } \\
\text { perform tender activities } \\
\text { Loss of income } \\
\text { Reduction in manpower hours } \\
\text { High cost of internet data }\end{array}$ & $\begin{array}{l}\text { Discourage public } \\
\text { sector agencies in } \\
\text { supporting } \\
\text { implementation of the } \\
\text { platform }\end{array}$ \\
\hline $\begin{array}{l}\text { Supplier } \\
\text { Organizations }\end{array}$ & $\begin{array}{l}\text { Efficient registration } \\
\text { Efficient bidding of contract } \\
\text { Well organized responses, submissions and } \\
\text { clarification of tenders } \\
\text { Enhance participation in auctions } \\
\text { Appeals on unsatisfied submitted tender. }\end{array}$ & $\begin{array}{l}\mathrm{Y} \\
\mathrm{Y} \\
\mathrm{Y} \\
\mathrm{N} \\
\mathrm{N}\end{array}$ & $\begin{array}{l}\text { High cost of internet data } \\
\text { Slow and unstable internet connectivity } \\
\text { Difficult to understand some platform } \\
\text { functionalities } \\
\text { High Illiteracy rate among service } \\
\text { providers }\end{array}$ & $\begin{array}{l}\text { Demoralizes staff in } \\
\text { support of platform } \\
\text { implementation }\end{array}$ \\
\hline
\end{tabular}

\subsection{Implemented Viewpoints and Responses}

It appears adhering to emerging international best practices is the only viewpoint that got implemented for the central government. The regulator had enhanced competition among supplier organizations and shortened procurement processes and cycles implemented. Procurement entities had almost all its viewpoints such as public agency registration, annual procurement plan preparation, and advertisement of tenders implemented on the e-procurement platform while supplier organizations had efficient registration, efficient contract bidding and well organized responses, 
tender submission as well as clarification of tenders viewpoints realized. It appears from the case study findings that apart from the realization of adhering to emerging international best practices that is influenced by the joining of global procurement bodies, no factor from outside the e-procurement application influenced the realization of the implemented viewpoints. The implemented viewpoints are realized as a result of activation of the e-procurement platform functionalities that are supposed to accomplish them. The study further seems to suggest that stakeholder attributes of power, legitimacy, and urgency did not enable the realization of implementing viewpoints and their corresponding responses.

The implication for achieving a limited number of viewpoints is that the benefits to be derived from the implementation of the e-procurement platform for stakeholder groups are likely to be limited. This suggests that the realization of limited stakeholder groups' viewpoints is likely to affect the benefits to be derived from digital transformation initiatives in the public sector. Another implication is that responses of stakeholders to e-procurement implementation are important source of information for determining its success. By inferences, this means that for digital transformation initiative in the public to be successful, stakeholder groups' responses are not to be taken for granted.

\subsection{Unimplemented Viewpoints and Responses}

Central government viewpoints that were not realized during the implementation were transformed provision of goods and services, enhanced procurement sanity, and improved financial management practices. Reduced corruption and procurement malpractices as well as promotion of environmental sustainable development were regulator viewpoints that were not achieved. While it appears none of the viewpoints of procurement entities were realized, enhanced participation in auctions, and lodging of appeals on unsatisfied submitted tender are supplier organizations' viewpoints that were not implemented.

Lack of interest on the part of the central government to carry out the e-procurement platform implementation, lack of infrastructure to host the eprocurement platform, lack of necessary ICT gadgets to carry out procurement activities, slow and unstable internet connectivity, difficulty in third party interconnectivity, loss of income and reduction in manpower hours, high level of corruption, high cost of internet data, and high illiteracy rate are key factors outside the e-procurement platform application that influenced the unsuccessful realization of the unimplemented viewpoints. Central government's lack of interest in the e-procurement platform led to a break in implementation of the platform for 2 years. Furthermore, the e-procurement platform is being hosted outside the country by the application service provider as a result of lack of relevant infrastructure to host the platform in Ghana. In addition, staffs of procurement entities and supplier organizations are unable to access the platform because of the lack of necessary ICT gadgets. Moreover, the high cost of internet data, and slow and unstable internet connectivity demoralize staff of procurement entities and supplier organizations to support the implementation of the e-procurement platform.

Also, difficulty in understanding some platform functionalities and high illiteracy rate in the country discourage supplier organizations to support the implementation of the platform. The study seems to suggest that the attributes of stakeholder such as power, urgency, and legitimacy did not influence the determination of the unimplemented viewpoints and their resultant responses.

What this implies is that until the relevant technological infrastructure is provided for in the country, the needed ICT education is encouraged and improved, and citizens are ready to embrace the use of ICT in their daily activities, it will be difficult for digital transformation initiatives to be carried out in the public sector.

\section{Discussions}

In relation to the research question and literature review, this section discusses the findings of the study. While stakeholder viewpoints are relevant for the effective understanding of e-procurement platform implementation [2], this study suggests that their responses to such initiatives sometimes run contrary to the viewpoints. It is evident from the case analysis that though some stakeholders are pleased with the eprocurement platform implementation because of the realization of some viewpoints, there is still skepticism about the success of the project. This is attributed to the situation where such initiatives in the public sector are abandoned because of lack of interest from central governments and the unwillingness of other key stakeholders to support such initiatives. Therefore, governments must ensure that digital transformation initiatives are carried out to their successful completion without a break in implementation. Also, relevant stakeholders are to be encouraged to support initiatives intended to transform the provision of goods and services in the public sector.

Furthermore, the success of public sector digital transformation projects hinges on how stakeholders 
view and respond to such initiatives [48]. Though stakeholders in the public sector have good expectations or viewpoints on digital transformation initiatives, they also have responses that may undermine such initiatives. This study throws light on the need for handlers of public sector digital transformation initiatives to not only examine the expectations of stakeholders, but also understand their responses which show how such initiatives are meeting the expectations or not. For instance, the widely acknowledged viewpoint of supplier organizations on using the e-procurement platform to successfully bid for tenders turn out not to be entirely met since some of them complain about the high cost of internet data, slow and unstable internet services, and the illiteracy rate in the country. Therefore, being able to separate viewpoints or expectations from responses and appreciate particularly the responses contributes to the understanding of how the interests of stakeholders can shape public sector digital transformation initiatives.

Again, this study shows that the unavailability of required ICT infrastructure affects digital transformation initiatives in the public sector. For example, the regulator indicated that apart from low financial reward that is cited for the lack of interest of public sector agencies to support the e-procurement platform implementation, the country lacked the appropriate ICT infrastructure which caused the central government to ask the application service provider to host the e-procurement platform in a foreign country. This is reiterated by [35] who observed that the absence of ICT infrastructure negatively impacts the transformation of public sector services. Thus, there is the need for government to provide a suitable ICT infrastructural environment when such public sector transformation initiatives are considered.

Summing up, the study presents the need for policy makers and practitioners of public sector institutions to critically examine stakeholder groups' interests during the implementation of digital transformation initiatives in order to understand the factors that shape such initiatives.

\section{Conclusion and Implications}

This research set out to understanding how stakeholders' viewpoints and responses shape digital transformation initiatives in the public sector. The originality of the paper lies in its focus to understand digital transformation initiatives in the public sector from the perspectives of stakeholders' viewpoints and responses considering that less literature on this exist in IS. Several findings emerge from the study with research, practice, and policy implications. Notably among them is that central government's lack of interest in such initiatives leads to break in their implementation which adversely affects the transformation of service provision in the public sector.

For research, this study has shown that the stakeholder theory is suitable for studying realities that involves different parties with diverse views and reactions. This study also extends the IS literature on implementation to the context of public sector digital transformation. Studies on public sector digital transformation initiatives are essential since they can help practitioners and policy formulators to better appreciate the barriers and enablers of government digitalization. For practice, understanding interested parties' viewpoints and responses to public sector digital transformation initiatives can shape how such projects must be carried out. It is important, therefore, for government institutions to take seriously the reservations of stakeholders when implementing digital government initiatives. For policy, this research has provided policy makers with useful feedbacks that will enable them develop policies that will guide the effective handling of digital transformation initiatives in the public sector. The study is limited by its single country focus. However, with the principles of interpretive study, the findings are applicable to developing countries with similar context. Future research can look at contextual factors such as economic, culture, and political and their mediating role on the implementation of e-procurement systems in the public sector.+

\section{References}

[1] Abdulkareem, A. K., "Challenges of E-Government Implementation in the Nigerian Public Service." , Journal of Creative Writing, 1(4), 2015, pp. 45-58.

[2] Ahmad, T., R. Aljafari and V. Venkatesh, "The Government of Jamaica's Electronic Procurement System: Experiences and Lessons Learned.", Internet Research, 29(6), 2019, pp. 1-18.

[3] Alghamdi, I., R. Goodwin and G. Rampersad, " EGovernment Readiness Assessment for Government Organizations in Developing Countries.", Computer and Information Science, 4(3), 2011, pp. 3-17.

[4] Al-Kharusi, H., S. Miskon and M. Bahari, "Factors influencing the engagement between enterprise architects and stakeholders in enterprise architecture.", Pacific Asia Conference on Information System (PACIS), 2016, pp. 1-12, Chiayi, Taiwan.

[5] Alomari, M., P. Woods and K. Sandhu, "Predictors for E-government Adoption in Jordan.", Information Technology \& People, 25(2), 2012, pp. 207-234. 
[6] Anthopoulos, L. G., C. G. Reddick, I. Giannakidou and N. Mavridis, "Why e-government projects fail? An analysis of the Healthcare.gov website.", Government Information Quarterly, 33(1), 2016, pp. 161-173.

[7] Besson, P. and F. Rowe, "Strategizing Information Systems-Enabled Organizational Transformation: A Transdisciplinary Review and New Directions.", Journal of Strategic Information Systems, 21(2), 2012, pp. 103-124.

[8] Beynon-Davies, P., I. Owens and M. D. Williams, "Information Systems Evaluation and the Information Systems Development Process.", Journal of Enterprise Information Management, 17(4), 2004, pp. 276-282.

[9] Bhattacherjee, A., C. J. Davis, A. J. Connolly and N. Hikmet, "User Response to Mandatory IT Use: A Coping Theory Perspective.", European Journal of Information Systems, 27(4), 2018, pp. 395-414.

[10] Bibi, D., J. Effah and R. Boateng, "Evaluation of a National Digital Location Infrastructure: Stakeholders' Perspectives in Ghana.", Twenty-fifth Americas Conference on Information Systems (AMCIS), 2019, pp. 1-9, Cancum, Mexico.

[11] Bigdelia, A. Z., M. M. Kamalb and S. Cesare, "Electronic Information Sharing in Local Government Authorities: Factors Influencing the Decision-Making Proess. ", Internatioanl Journal of Information Management, 33(1), 2013, pp. 816-830.

[12] Boddy, D. and D. A. Buchanan, "Managing New Technology.", 1986, B. Blackwell.

[13] Bwalya, K. J., T. D. Plessis and C. Rensleigh, "Egovernment implementation in Zambia: Prospects. Transforming Government.", People, Process and Policy, 8(1), 2014, pp. 101-130.

[14] Chan, C., S. Pan and C. W. Tan, "Managing Stakeholder Relationships in an E-Government Project. ", Americas Conference on Information Systems (AMCIS), 2003, pp. 98

[15] Choi, H., M. J. Park, J. J. Rho and H. Zo, "Rethinking the assessment of e-government implementation in developing countries from the perspective of the designreality gap: Applications in the Indonesian e-procurement system.", Telecommunications Policy, 40(7), 2014, pp. 644660.

[16] Ciriello, R. F., A. Richter and G. Schwabe, "Digital Innovation.", Business Information Systems Engineering, 60(6), 2018, pp. 583-589.

[17] Constantinides, P. and M. Barrett, "Information Infrastructure Development and Governance as Collective Action.", Information Systems Research, 26(1), 2014, pp. 40 58 .

[18] Cottrill, K., "E-government Grows.", Traffic World, 265(10), 2001, pp. 19-25.

[19] Currie, W. N., Pouloudi and E. A. Whitley, "Entangled stakeholder roles and perceptions in health information systems: a longitudinal study of the UK NHS N3 network.", Journal of the Association for Information Systems, 17(2), 2016, pp. 107-161.

[20] Donaldson, T. and L. E. Preston, "The Stakeholder Theory of the Corporation - Concepts, Evidence, and Implications.", Academy of Management Review, 20(1), 1995, 65-91.

[21] Dwivedi, Y. K., D. Wastell, S. Laumer, H. Z. Henriksen, M. D. Myers, D. Bunker, "Research on Information Systems Failures and Successes: Status Update and Future Directions.", Information Systems Frontiers, 17(1), 2015, 143-159.

[22] Effah, J. and H. Nuhu, "Institutional Barriers to Digitalization of Government Budgeting in Developing Countries: A Case Study of Ghana.", The Electronic Journal of Information Systems in Developing Countries, 82(5), 2017, $1-17$.

[23] Flak, L. S. and J. Rose, "Stakeholder Governance: Adapting Stakeholder Theory to e-Government.", Communications of the Association for Information Systems, 16(1), 2005, pp. 31.

[24] Flak, L. S., S. Nordheim and B. E. Munkvold, "Analyzing Stakeholder Diversity in G2G Efforts: Combining Descriptive Stakeholder Theory and Dialectic Process Theory.", 39th Hawaii International Conference on System Sciences, 2006, pp. 1-10, Kauai, Hawaii.

[25] Gimpel, H., S. Hosseini, R. X. Huber, L. Probst, M. Röglinger and U. Faisst, "Structuring Digital Transformation: A Framework of Action Fields and its Application at ZEISS.", Journal of Information Technology Theory and Application, 19(1), 2018, pp. 31-56.

[26] Gmelch, O. and G. Pernul, "A Portal-Based Approach for User-Centric Legacy Application Integration in Collaborative Environments.", International Conference on Wirtschaftsinformatik, 2011, pp. 1-10, Zurich, Swtizerland.

[27] Grant, G. and D. Chau, "Developing a Generic Framework for E-Government.", Advanced Topics in Information Management, 18(5), 2006, pp. 72-94.

[28] Holgersson, J. and F. Karlsson,"Public E-Service Development: Understanding Citizens' Conditions for Participation.", Government Information Quarterly, 31(3), 2014, 396-410.

[29] Hughes, M., M. Scott and W. Golden, "Implementation Strategies for E-Government: A Stakeholder Analysis Approach.", 12th European Conference on Information Systems (ECIS), 2004 , pp. 203-215, Turku, Finland.

[30] Ingram Bogusz, C. and M. Morisse, "How Infrastructures Anchor Open Entrepreneurship: The Case of Bitcoin and Stigma.", Information Systems Journal, 28(6), 2018, pp. 1176-1212.

[31] Introna, L., and A. Pouloudi, "Privacy in the Information Age: Stakeholders, interests and values.", Journal of Business Ethics, 22(1), 1999, pp. 27-38. 
[32] Klein, H. and M. Myers, "A set of principles for conducting and evaluating interpretive field studies in information systems.", MIS Quarterly, 23(1), 1999, pp. 67-93.

[33] Lindgren, I. and G. Jansson, "Electronic Services in the Public Sector: A Conceptual Framework.", Government Information Quarterly, 30(2), 2013, pp. 163-172.

[34] Mannion, M., B. Keepence and D. Harpe, "Domain Requirements Definition Using Viewpoint.", IEEE Software, 1998, pp. 95-102.

[35] Matt, C., T. Hess, and A. Benlian, "Digital Transformation Strategies.", Business and Information Systems Engineering, 59(5), 2015, 339-343.

[36] Mitchell, R. K., B. R. Agle and D. J. Wood, "Toward a Theory of Stakeholder Identification and Salience: Defining the Principle of Who and What Really Counts.", Academy of Management Review, 22(4), 1997, pp. 855-886.

[37] Myers, M. D., "Qualitative research in information systems.", MIS Quarterly, 21(2), 1997, pp. 241-242.

[38] Nkohkwo, Q. N. and M. S. Islam, "Challenges to the Successful Implementation of e-Government Initiatives in Sub-Saharan Africa: A Literature Review.", Electronic Journal of E-Government, 11(2), 2013, pp. 255-267.

[39] Platisa, G. and N. Balaban, "Methodological Aproach to Evaluation of Information System Functionality Performances and Importance of Successfulness Factor Analysis.", The International Scientific Journal of Management Information System, 4(2), 2009, pp. 11-17.

[40] Pouloudi, N., W. Currie and E. Whitley, "Entangled Stakeholder Roles and Perceptions in Health Information Systems: A Longitudinal Study of the U.K. NHS N3 Network.", Journal of the Association for Information Systems, 17(2), 2018, pp. 107-161.

[41] Rodon, J. and L. Silva, "Exploring the Formation of a Healthcare Information Infrastructure: Hierarchy or Meshwork?", Journal of the Association for Information Systems, 16(5), 2015, pp. 394-417.

[42] Sarker, M. N., M. Wu and M. A. Hossin, "Smart Governance through Bigdata: Digital Transformation of Public
Agencies.", International Conference on Artificial Intelligence and Big Data, 2018, pp. 62-70, Chengdu, China.

[43] Sedera, D., G., G., \& Chan, T. (2003). Knowledge management for ERP success. Proceeding of the 7th. PACIS. Adelaide, Australia.

[44] Shareef, S., "The Adoption of Cloud Computing for e-Government Initiative in Regional Governments in Developing Countries.", 13th European Conference on eGovernment, 2013, pp. 455-461, Como, Italy.

[45] Singletary, L., S. Pawlowski and E. Watson, "What is applications integration?", Understanding the perspectives of managers, IT professionals, and End Users.", In Proceedings of the 9th. AMCIS, 2003, Tampa, Florida.

[46] Skog, D., A. Wimelius and H. Sandberg, "Digital Disruption.", Business and Information Systems Engineering, 60(5), 2018, pp. 431-437.

[47] Sun, M. and Y. Li, "Formal Modeling and Verification of Complex Interactions in e-Government Application.", ICEGOV, 2014, pp. 506-507, Guimaraes, Portugal, Association of Comuputing Machinery.

[48] Tan, C., S. L. Pan and E. T. Lim, "Managing Stakeholder Interests in an E-Government Project: Lessons Learned from a Singapore E-Government Project.", Journal of Global Information Management, 13(1), 2005, pp. 31-55.

[49] Tanniru, M., J. Khuntia and J. Weiner," Hospital Leadership in Support of Digital Transformation.", Pacific Asia Journal of the Association for Information Systems, 10(3), 2018, pp. 1-24.

[50] Voorberg, W., V. Bekkers and L. Tummers, "A systematic review of Co-creation and Co-production: Embarking on the Social Innovation Journey.", Public Management Review, 17(9), 2015, pp. 1333-1359.

[51] Walsham, G., "Interpretive Case Studies in IS Research: Nature and Method.", European Journal of Information Systems, 4(2), 1995, pp. 74-81. 